\title{
AVALIAÇÃO DO EFEITO FUNGICIDA DE ÓLEOS ESSENCIAIS SOBRE A PRODUÇÃO DE ESPOROS DO FUNGO Fusarium solani
}

\author{
Athaise Ferreira de Lima' \\ Tatiane Paulino $\mathrm{Cruz}^{2}$ \\ Mayse Margarida Ferreira ${ }^{3}$ \\ Adilson Vidal Costa ${ }^{4}$ \\ Waldir Cintra de Jesus Junior ${ }^{5}$ \\ Willian Bucker Moraes ${ }^{6}$ \\ Vagner Tebaldi de Queiroz ${ }^{7}$ \\ Fábio Ramos Alves ${ }^{8}$
}

Resumo: O fungo Fusarium solani é um patógeno de solo que ataca inúmeros hospedeiros e sobrevive saprofiticamente em restos de cultura o que dificulta o seu controle. Surge então a necessidade de formas de controle deste patógeno, os óleos essenciais possuem alta atividade biológica e potencial para o controle de doenças de plantas, possuindo também baixa ou nenhuma toxidez aos mamíferos. $O$ experimento foi conduzido em esquema fatorial, em delineamento inteiramente casualizado (DIC) em esquema fatorial $9 x$ $6+1$ (nove óleos, seis alíquotas de cada óleo e uma testemunha). Em todos os tratamentos foram utilizadas cinco repetições. Após as avalições observou-se que os óleos de canela e cravo-da-índia apresentaram inibição total na produção do fungo F. solani UENF/CF 241.

Palavras-chave: Controle alternativo; Fusariose; Syzygium aromaticum; Cinnamomum zeylanicum.

\footnotetext{
1 Universidade Federal do Espírito Santo, Brasil. E-mail: athaisef@hotmail.com.

2 Universidade Federal do Espírito Santo, Brasil. E-mail: agronomapaulino@hotmail.com.

3 Universidade Federal do Espírito Santo, Brasil. E-mail: mayseferreira@live.com.

${ }^{4}$ Universidade Federal do Espírito Santo, Brasil. E-mail: avcosta@hotmail.com.

5 Universidade Federal do Espírito Santo, Brasil. E-mail: wcintra@yahoo.com.

${ }^{6}$ Universidade Federal do Espírito Santo, Brasil. E-mail: willian.fito@gmail.com.

7 Universidade Federal do Espírito Santo, Brasil. E-mail: vagnertq@gmail.com.

8 Universidade Federal do Espírito Santo, Brasil. E-mail: fabioramosalves@yahoo.com.br.
} 